\title{
PROBLEM-BASED LEARNING IMPLEMENTATION: IMPROVEMENT IN LEARNING PROCESS AND RESULTS IN VOCATIONAL HIGHER EDUCATION
}

\author{
Muhammad Nurtanto ${ }^{1}$, Soffan Nurhaji ${ }^{2}$, Jamil Abd Baser ${ }^{3}$, and Yadin ${ }^{4}$ \\ ${ }^{12}$ Department of Mechanical Engineering Education, Universitas Sultan Ageng Tirtayasa, Banten, Indonesia \\ ${ }^{3}$ Faculty of Technical Education,Universiti Tun Hussein Onn Malaysia, Malaysia \\ ${ }^{4}$ Department of Automotive Engineering, Universitas Negeri Makasar, Indonesia \\ E-mail: mnurtanto23@untirta.ac.id
}

\begin{abstract}
Problem Based Learning (PBL) is a learning method considered to be capable of changing the students' perception in facing the challenges of the 21st century. This study was aimed to improve soft skills in the form of critical thinking, motivation, and group dynamics and hard skills in the form of psychomotor ability by applying PBL. This study was designed with an action research design. The research subjects were 30 students at the age of 19 to 22 years old. Data were collected with performance appraisal, observation sheet and questionnaires. The results indicated that (1) the students' critical thinking works effectively during problem identification and problem hypothesis, (2) increasing motivational ability indicated by time discipline, and (3) improved group dynamics skills during group discussions and groups activities. The results for psychomotor ability showed an increase of 16.6 or $17 \%$. This confirmed that PBL improved the students' soft skills and hard skills reflected in positive and effective group activities.
\end{abstract}

Keywords: problem-based learning, critical thinking, motivation, group dynamics

\section{INTRODUCTION}

Problem Based Learning is a newly developed method in Indonesian education. In vocational higher education PBL is one of the methods recommended to be developed for learning. The fact is that PBL has been utilized for almost 30 years and has been developed for the education field [1]-[3]. Several expert practitioners discovered the significant impact of PBL implementation [4] and then it experienced a good development for the learning process [5]. The benefits of PBL are (1) learning atmosphere is more active and student-centered [6], [7], (2) increasing the ability of critical, creative and innovative thinking [[8]-[11], (3) encouragement of learning motivation [12], and (4) group dynamics is well performed [13].

Moreover, the PBL concept is supporting competence theoretically and in practice [14], [15]. This model is also known as inductive learning that can stimulate better learning, especially in higher discipline compared to the conventional concept. Brown [16] stated that: (a) PBL will be a very suitable learning approach for the $21^{\text {st }}$ century students; (b) PBL is a solid approach because it focuses on the students, where they learn and use their cognitive skills and critical thinking; and (c) this is a learning strategy that is productive. Therefore, PBL is recommended as a productive and continually developing method among educators.

Problem Based Learning success certainly requires suitable learning atmosphere and characteristics. When PBL is implemented without proper control, the outcomes will not be optimum or even declining in quality. Some characteristics that need to be strictly observed and implemented are (1) the problem should relate to the real-world condition [17], (2) the collaborative groups should consist of 6 to 8 persons [18], (3) problems should cover several fields of study [19], (4) it should encourage problem solving and team communication [20]. Moreover, PBL characteristics from Savery [15] consist of 10 essential points namely (1) 
students should feel responsible for their learning, (2) problem simulations in the PBL should not be structured and allow free researches, (3) learning should integrate several fields of knowledge or classes, (4) collaboration is important, (5) what students learned during their independent learning should be implemented for the problems with re-analysis and resolution, (6) there should be a closing analysis from what they have learned from working out the problems and also discussion about what principal they have studied, (7) selfassessment and peer assessment should be conducted for every problem solution and at the end of every curricular unit, (8) Activities during PBL should be valued in the real world, (9) student exam should measure their development in the PBL objectives, and (10) Problem-Based Learning should be the pedagogic basis of the curriculum and not be part of didactic curriculum.

Gasoline motor curriculum is the incorporation of theoretical and practical concepts with the development of soft and hard skills in the learning process in daily life, vehicle problems often arise. Gasoline motor is made up of various interrelated scientific disciplines. The major contexts are divided into three disciplines, engine, electrical and chassis. Every discipline is made up of systems and components that are inter-related in their working mechanisms. Gasoline motor practice incorporates two related parts and both need maintenance. They are the engine system and electrical system. Not all concepts of engine or electrical are studied, but only the concept of ignition triangle should be understood. For instance, the spark should be strong enough which falls into the ignition system, oxidation or ignition as in the mixing of fuel and air, and also high compression which is related to the valve mechanism. Learning for these competence requires analytical capability, high level of critical thinking and even scientific dimension in the level of procedural and metacognitive should be mastered.

Problem Based Learning has a role in the gasoline motor curriculum. This requires the ability of facilitators or the role of teachers in packaging problems that often arise in the field or at work [21]. The gasoline motor practice competence refers to the competency standards of Indonesian National Qualification Framework.Problems also often arise due to differences in size or component changes due to excessive vehicle use that resulted in worn-out components. The size specification is worn out, and it needs adjustment or re-maintenance and even component replacement when it exceeds the specification limit. The purpose of the adjustment is to return the machine to its optimum performance.

The above issues can be used as the material for learning activities thus the students are expected to analyze problems, build hypotheses, perform tests, summarize the results and even discuss with other groups with different problems. As explained by Fogarty [22] and Tan [23], the PBL implementation include (1) meet the problem; (2) generate questions; (5) make hypotheses; (6) rephrase the problem; (7) generate alternative solutions; and (8) present the solutions, preferably with justifications. Summarized by Phumeechanya \& Wannapiroon [24], five actions in the PBL are (1) study the content, (2) present the problem, (3) problem-solving planning, (4) problem solving, and (5) identify generalizations and principles derived from studying the problem. Based on the opinion of practitioners, the implementation of PBL on the gasoline motor curriculum use the general formula from Sharma [25] with the stages presented in Table 1. 
Table 1. Stages in PBL Implementation and Activities

\begin{tabular}{|c|c|c|}
\hline PBL Stages & Facilitator Activities & Students Activities \\
\hline $\begin{array}{l}\text { Stage } 1 \\
\text { orienting students to } \\
\text { the problems }\end{array}$ & $\begin{array}{l}\text { a. Facilitator explains the objective of gasoline } \\
\text { motor practice, learning stages, learning } \\
\text { facilities, and target } \\
\text { b. Facilitator motivates the role of practice in the } \\
\text { future }\end{array}$ & $\begin{array}{l}\text { a. Students analyze their requirements } \\
\text { and starting point of the problem }\end{array}$ \\
\hline $\begin{array}{l}\text { Stage } 2 \\
\text { organizing students for } \\
\text { the study }\end{array}$ & $\begin{array}{l}\text { c. Facilitator divides students into groups of 6-8 } \\
\text { people } \\
\text { d. Explains preliminary problems that are found } \\
\text { in the engine }\end{array}$ & $\begin{array}{l}\text { Discuss in the team and appoint the } \\
\text { team-leader } \\
\text { Conduct preliminary experiment }\end{array}$ \\
\hline $\begin{array}{l}\text { Stage } 3 \\
\text { assisting independent } \\
\text { and group } \\
\text { investigation }\end{array}$ & $\begin{array}{l}\text { e. Encourages students to use various information } \\
\text { f. Encourages students to do tests on the gasoline } \\
\text { motor } \\
\text { g. Encourages students to seek explanations and } \\
\text { solutions }\end{array}$ & $\begin{array}{l}\text { d. Actively participate in using } \\
\text { information media and link the } \\
\text { problems } \\
\text { e. Using the measuring instruments and } \\
\text { safety gear as procedure and start } \\
\text { collecting preliminary data } \\
\text { f. Build hypotheses for the problems } \\
\text { found and then solve them }\end{array}$ \\
\hline $\begin{array}{l}\text { Stage } 4 \\
\text { developing and } \\
\text { presenting reports, } \\
\text { videos, models, etc. }\end{array}$ & $\begin{array}{l}\text { h. Helps students plan and prepare the experiment } \\
\text { results }\end{array}$ & $\begin{array}{l}\text { Communicate among students } \\
\text { Hold group discussion } \\
\text { Prepare question sheets }\end{array}$ \\
\hline $\begin{array}{l}\text { Stage } 5 \\
\text { analyzing and } \\
\text { evaluating the problem- } \\
\text { solving process. }\end{array}$ & $\begin{array}{l}\text { Reflects on the investigation that has been } \\
\text { conducted }\end{array}$ & $\begin{array}{l}\text { Take notes and listen to the } \\
\text { conclusion and evaluate the result of } \\
\text { group works }\end{array}$ \\
\hline
\end{tabular}

\section{METHOD}

This is a classroom action research based on Mc Taggart [26] and Kemmis \& McTaggart [27] consisting of three cycles with the reflection stage done at the end of the action. The study was conducted in the Department of Engineering Education at Banten in the Sixth semester. The students are 19 to 22 years old. Steps in this study were based on a modified action cycle proposed by Eliott [28] presented in Figure 1.

The target population of this study consisted of 30 students of Mechanical Engineering Education in the Gasoline Motor Practice Curriculum. The learning groups consist of 6 to 9 people. Students form the groups on their own to make the learning as their conditions, and they can work in the team. The results of this study are utilized to observe the improvement brought by PBL. Therefore it can be presented as a recommendation for other subjects with the same characteristics. The established team is then elected one person as a steering committee or acting as chairman [13], [29]. The chairman plays the same role as the other learners but has a more dominant role during team conditioning (discussion, job sharing) as well as communicating with the facilitator.

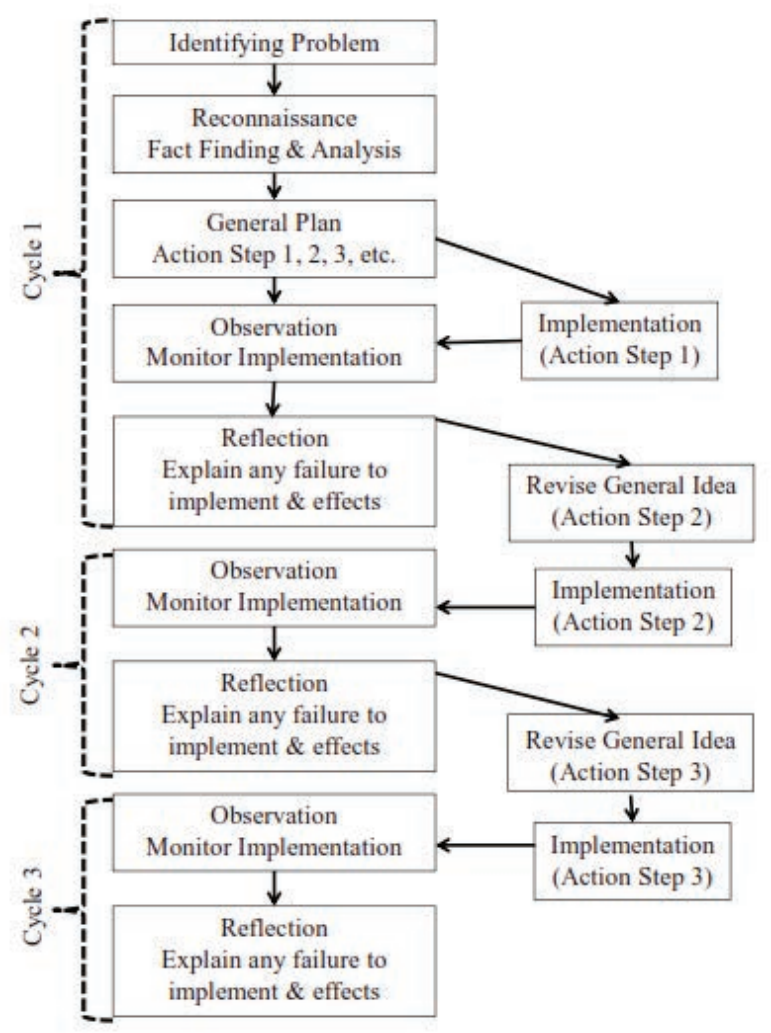

Figure 1. Steps in Modified Action Cycle 
Before the PBL begins, the facilitator explains direction and actions to be taken during the learning process. The performance appraisal sheets with the criteria of tools usage and work attitudes, ability to analyze a job, speed to complete the task, the ability to read pictures and symbols, and suitability of form were prepared for the end of the session [30]. This is for evaluation of the PBL method with a rating scale of $0,1,2$, and 3 . Next, during the PBL, collaborators, and facilitators conducted observations using observation sheets for the critical thinking, motivation and group dynamics. It is in the form of 12 questionnaires consisting of 4 critical thinking indicators, three motivational indicators, and five indicators of group dynamics with Likert scale 1 to 5 . The PBL will be categorized as successful when the scores are in the good enough category.

Students, throughout the process, evaluate themselves based on their experiences and perceptions. Hard skill assessment is done by the facilitator using observation method on the process and the results that are presented by students during the learning process with PBL. Assessment of critical thinking will observe the ability of individuals to build problems hypotheses, present information, identify problems, and also the results of group discussions. Motivation is assessed based on
Participation in answering or expressing opinions, completing tasks and timeliness. While group dynamics are scored by peer encouragement to communicate, listening and pay attention to others, dominance in group discussions, and cooperation comfort. The concept map of PBL Rating on Motorcycle Gas Curriculum is presented in Figure 2. The quantitative data is then further analyzed by presenting the percentage and then conversed descriptively. These are done in the beginning and at the end of data collection [31]-[34].

\section{RESULTS AND DISCUSSION}

Problem Based Learning Implementation in each cycle of the action is observed by facilitators and collaborators to see the students' thinking ability. Indicators that were observed consist of four aspects, namely (1) the ability of problem identification, (2) the ability to build hypotheses in PBL, (3) the ability to present information source correctly, and (4) discussion result with the group. All four aspects above become the measure to determine the student's ability for critical thinking when presented with problems during the learning process in gasoline motor curriculum. The improvements observed for each cycle are summarized in Table 2.

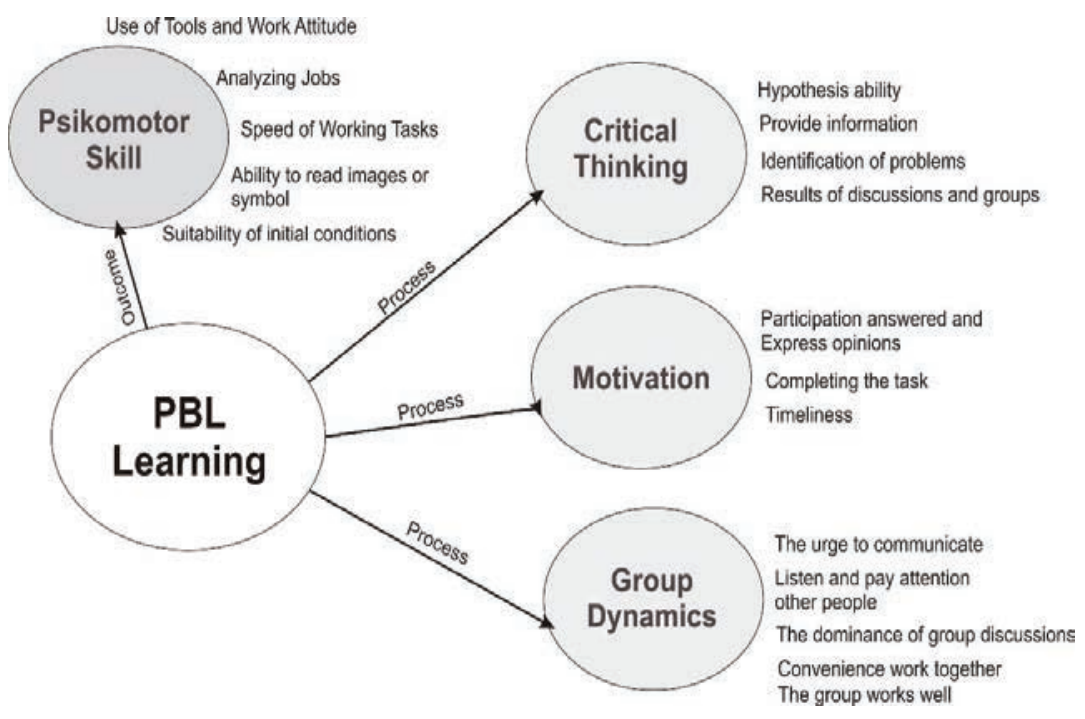

Figure 2. Concept Map of PBL Rating on Motorcycle Gas Curriculum 
Table 2. Improvement in Critical Thinking Ability with PBL

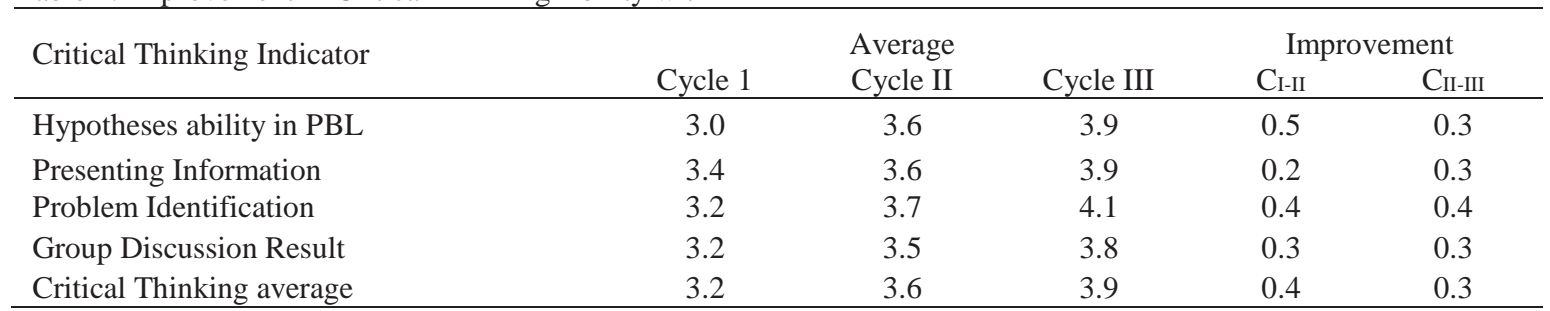

Data analysis presented in Table 2 shows the improvement in every cycle. The overall average for cycle 1 for assessment in the ability for critical thinking is 3.2 categorized as good enough. Failure analysis for cycle I resulted in an improvement of the score. It becomes 3.6. That is increase 0.4. Furthermore, to observe the influence of action more deeply, a reflection of cycle II bring result as much as 3.9, an improvement of 0.3 .

Based on the indicators used as the benchmark for each cycle, they all are in the good enough category. This means that the minimum requirements have been met. The problem identification ability based on cycles are 3.2, 3.7, and 4.1 respectively. The increased span is 0.9. Hypothesis building ability based on cycles are 3.0, 3.6, and 3.9 respectively, the increased span is 0.9 . The information sources proposal ability based on cycles are 3.4, 3.6, and 3.9 respectively, the increased span is 0.5 . While the result of the group discussion based on cycles is $3.2,3,5$, and 3.8 respectively, the increased span is 0.6. The students' ability in identifying problems and determining hypotheses in PBL is good. The ability of critical thinking is considered good and can be observed from the problem identification. The success of this category in each cycle is presented in Figure 3.

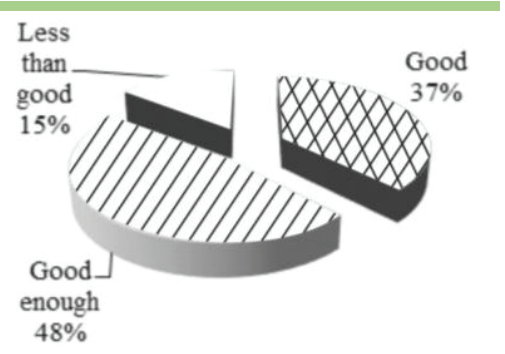

(a)

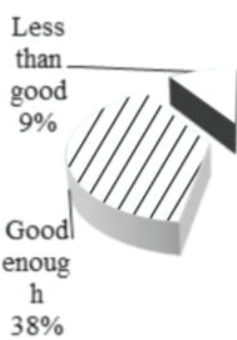

(b)

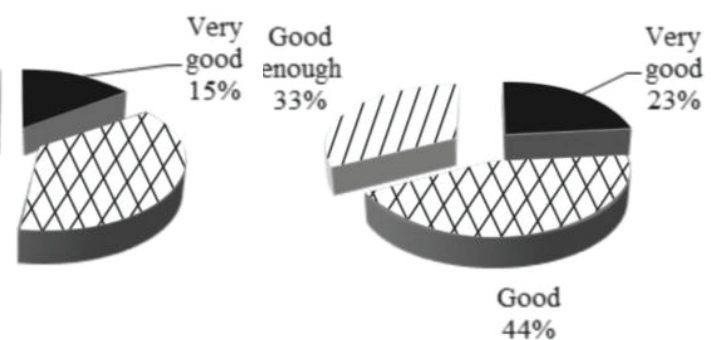

(c)

Figure 3. Critical Thinking Score Distribution in (a) Cycle I, (b) Cycle II, and (c) Cycle III

In cycle I, $15 \%$ of 30 students are in the category of less than good. Reflection based on the input of collaborators is then applied in cycle II that resulted in 9\% the category of less than good. Reflection is done again, and some inputs are used as a reference for cycle III that can overcome the less than good condition. In the good enough category, there is a reduction after each cycle. First, it is $48 \%$ and then $38 \%$ and finally $33 \%$. The improvement can be observed in the good category, from $37 \%$ to $39 \%$, and in the end, it is $44 \%$. The very good category, with $0 \%$ increased to $15 \%$ and ended up at $23 \%$. The success of PBL to improve critical thinking cannot be separated from the students desire to demonstrate better learning quality. PBL is a good method to well underway to improve the critical thinking and more active learning.

Motivation data collection was based on observations by collaborators and facilitators during the PBL classes. Some indicators of students' motivation are (1) participation in answering and expressing opinions, (2) task completion, and (3) timeliness. Students motivation improvement is observed in cycle II 
and cycle III that was conducted based on the result of reflection from the previous cycle. Researchers assumed that the critical thinking improvement influent linearly the student's motivation. Besides, PBL plays an active role in the independent environment as well as in groups. The increase in each indicator for each cycle can be observed in Table 3 .

Table 3 shows the increase in each cycle. Motivation is shown in cycle I with an average of 3.0 in the good enough category threshold. Indicator analysis shows failing at timeliness. Learning in a PBL class is the first experiential learning, requiring adaptation, especially activities related to the motivation, it needs special direction from the facilitator. These results serve as a rationale and an improvement basis for cycle II. Facilitators and collaborators determined strategies for each indicator, namely rewarding an active team, and limiting the time for the tasks.

The strategy was then applied in cycle II. It obtained a score of 3.5, increasing 0.5 (scale 1 to 5) from the previous cycle. Each indicator has met the minimum requirement "good enough". Application of the strategy is considered effective. Collaborators and facilitators reflected on the results of the second cycle as considerations for cycle III. Implementation of cycle III gives satisfactory results, PBL gives a positive response to motivation. It is indicated by the scale of 4 . Those are the completion of tasks and timeliness. Besides, the increase in cycle III is 0.5 compared to the previous cycle of 3.5. The increase shown during all PBL cycles is 1.0.

Table 3 shows an increase in motivation for each cycle. Motivation to answer and express an opinion in cycle I, cycle II and cycle III are 3.0; 3.,4; and 3.8 respectively. In such an improvement, the motivation is increasing in stable manners. To make the motivation improves in each cycle, it needs a facilitator who is actively developing the student's motivation. In the motivation indicator of task completion, the score for three cycles is 3.2, 3.6, and 3.6. It shows a steady increase in every cycle. While the motivation indicator of responsibility and discipline in turning the result timely, the results are 2.9, 3.6, and 4.1. In this motivation indicator, it can be observed that discipline supports PBL in the gasoline motor curriculum. Figure 4 shows the motivation score distribution in each cycle.

Table 3. Improvement in Motivation with PBL

\begin{tabular}{lccccc}
\hline \multirow{2}{*}{ Critical Thinking Indicator } & \multicolumn{2}{c}{ Average } & \multicolumn{3}{c}{ Improvement } \\
& Cycle 1 & Cycle II & Cycle III & CI-II & CII-III \\
\hline Participation in answering and sharing opinions & 3.0 & 3.4 & 3.8 & 0.5 & 0.4 \\
Task completion & 3.2 & 3.6 & 4.0 & 0.4 & 0.4 \\
Timeliness & 2.9 & 3.6 & 4.1 & 0.7 & 0.5 \\
Motivation average & 3.0 & 3.5 & 4.0 & 0.5 & 0.4 \\
\hline
\end{tabular}

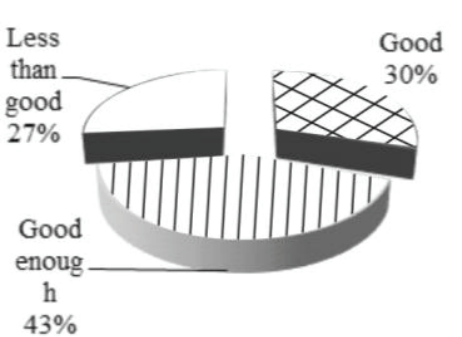

(a)

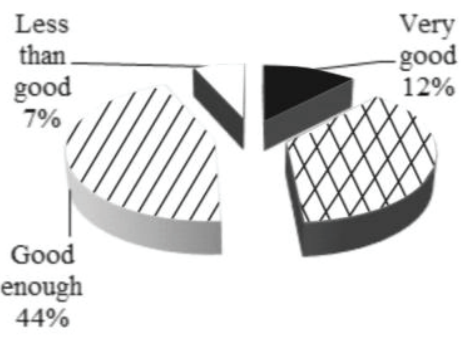

(b)

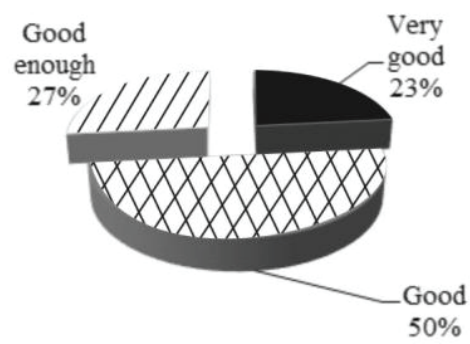

(c)

Figure 4. Motivation Score Distribution (a) Cycle I, (b) Cycle II, dan (c) Cycle III 
Cycle I has $27 \%$ (30) in the category of less than good. The input of the collaborators had a positive impact with the reduction in cycle II to $7 \%$ (30). The reflection is further enhanced in cycle III, giving a positive result. There is no more students are in the less than good category. The least of them are good enough, which progress from cycle I to cycle III from $43 \%$ to $44 \%$ and end up decreasing to $27 \%$. The indicators in the good category progress from $30 \%$ to $37 \%$ and then $50 \%$. The very good category starts with $0 \%$ to become $12 \%$ and then $23 \%$. So all aspects have met the requirement. The success of PBL in increasing students motivation is reflected in the participation of inquiring, task completion, and time discipline. Thus students can take responsibility in the learning environment. Success in improving motivation is influenced by the involvement of a stimulate students. The previous researcher applied PBL in Technical Drawing also discovered that PBL could increase learning motivation [35].

Group dynamics data were taken during the PBL process in the motor gasoline curriculum. Indicators of group dynamics consisted of (1) encouraging teams, (2) listen and pay attention, (3) group discussions dominance, (4) comfort in cooperation, and (5) the team works well. The improvement of each cycle is based on reflection results to improve the group dynamics at the next cycle. The result of group dynamics is shown in the following Table 4.

Data analysis in Table 4 shows group dynamics improvement in PBL class for each cycle. For all cycles, all indicators meet the requirement with scores of $\geq 3.0$. This means all indicators are in the good enough category at the least. The scores in cycle I, cycle II and cycle III were 3.3, 3.7 and 4.1 respectively. The overall increase is 0.7 on a scale of 1 to 5 .

Group dynamics is considered to be able to bring positive changes. In the group dynamics, the better improvement is on cycle I to cycle II with an increase of 0.5 for encouraging team members to communicate and in group discussion dominance. It seems that the problems presented in the PBL class for gasoline motor curriculum bring unprecedented experiences. Therefore it stimulates activity in the group to find a solution for the problem.

Furthermore, in cycle II to cycle III of group dynamics, the best improvement is in comfort of cooperation. The developed indication is that PBL stimulates more on communication, performance, and teamwork. Overall, PBL supports group dynamics more effectively. The group dynamics score distribution is presented in Figure 5.

Table 4. Improvement in Group Dynamics with PBL

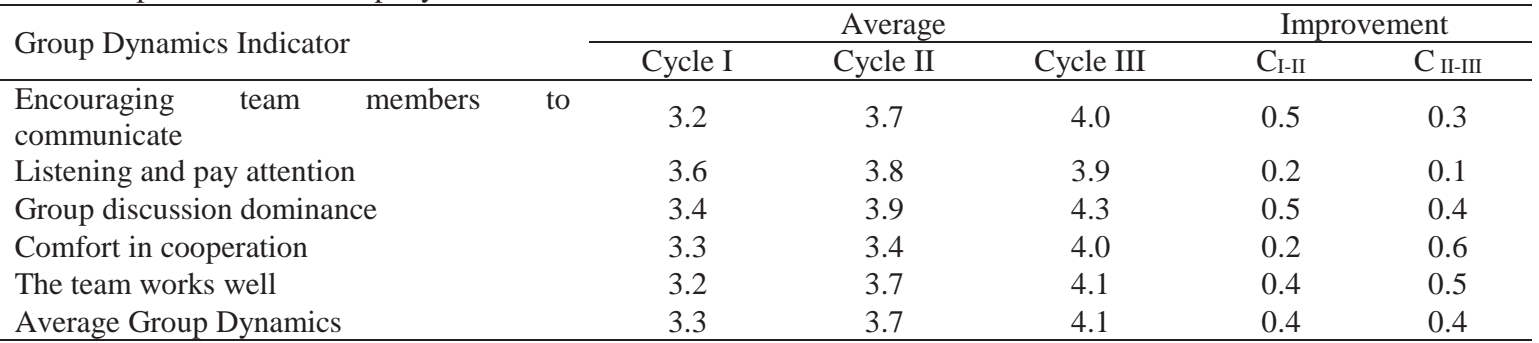

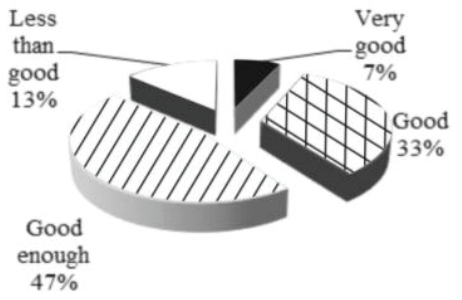

(a)

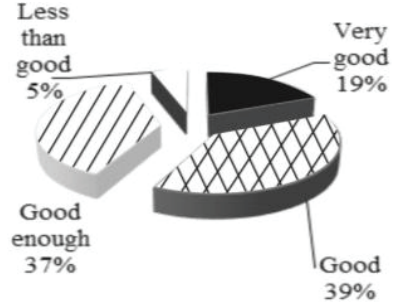

(b)

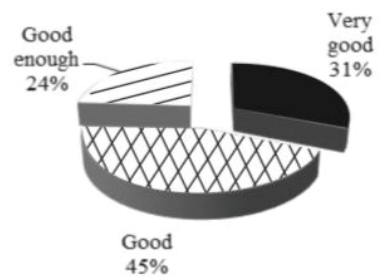

(c)

Figure 5. Group Dynamics Score Distribution (a) Cycle I, (b) Cycle II, and (c) Cycle III 
The success of the group dynamics by the assessment indicator is presented in Figure 8. Assessment is rated to be successful if all indicators are in the good enough category at least. Thus, improvements are made from cycles to cycles. Cycle 1 indicates the less than good indicator was $13 \%$. The reflection of the collaborators and facilitators has decreased it to $5 \%$ while the cycle III it can be eliminated well. The assessment of the good enough category in the first cycle was $47 \%$, and then it was changed to $37 \%$ and then finally decreasing again to $24 \%$. These decreases bring a positive impact on the other category. In the good category, at first it is 33\%, then 39\% and finally, in the last cycle, it is $45 \%$. Same thing with the very good category that starts with $7 \%$, then $19 \%$, and ends up at $31 \%$. The entire cycles show the group dynamics of the gasoline motor curriculum experience a positive impact and improvement.

The PBL process is assessed through the performance assessment sheet to observe the psychomotor abilities in the group from process start to the end. Assessment indicators consist of five competencies namely (1) mastery of tools and attitudes, (2) the problem analysis ability, (3) the accuracy of doing and completing tasks, (4) the ability to read problem situations, and (5) the compatibility of preengine conditions in the PBL class. From those indicators, then it is simplified into three indicators, point 1 , basic skill ability; point 2 , 3 and 4, field mastery ability; and point 5, the final result of problem-solving. The score for psychomotor ability by cycles is shown in Figure 6.

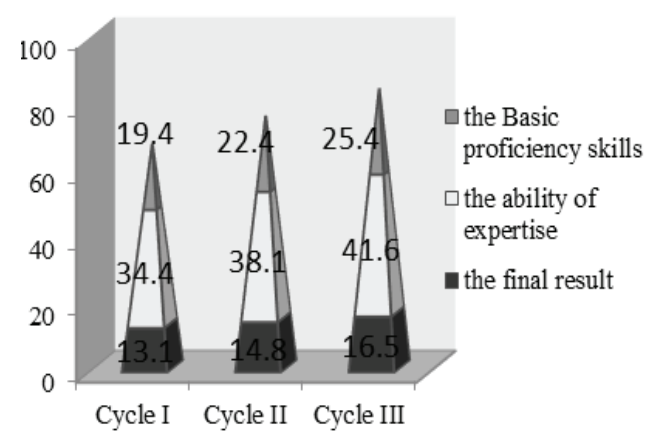

Figure 6. Psychomotor Ability Score Based on Indicator
Results of the psychomotor capability of the cycle I on basic skills, the field mastery ability, and the final result of problem-solving are $13.1,34.4$, and 19.4 respectively with a total of 66.9. Cycle II see an increase, respectively 14.8, 38.1, and 22.4 for a total of 75.3 . While Cycle III also shows an increase of 16.5, 41.6, and 25.4 with a total of 83.5. Figure 7 shows the psychomotor ability score. The improvement of psychomotor ability is 66.9 to 75.3 and then 83.5; that is $17 \%$. Thus the PBL in the gasoline motor curriculum gives a good effect. Previous PBL research was applied to the ignition system and was able to increase psychomotor ability by $5.03 \%$ [36]. PBL is a learning method that runs effectively on Automotive learning.

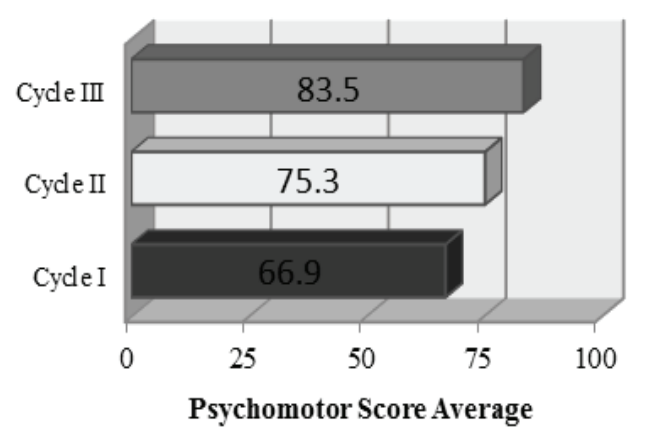

Figure 7. Psychomotor Ability Score

\section{CONCLUSION}

The learning process in the gasoline motor curriculum with the application of PBL demonstrates a positive improvement in some abilities including (1) increased critical thinking skills from 3.2 to 3.9 with improved soft skills on problem identification and hypotheses development in PBL, (2) improved motivation during action from 3.0 to 4.0 with soft skills improvement in the form of timeliness, and (3) increased group dynamics during process from 3.3 to 4.1 with improvement of soft skill in the form of dominance in discussion and how well the groups work. All those measurements used a Likert scale of 1 to 5 . All 30 students demonstrate the score categorized at least as good enough during the entire cycles of PBL 
classes. PBL supports the learning process to run actively. The learning results of the gasoline motor curriculum through PBL show an increase of $17 \%$ with assessment scores of each indicator are 66.9, 75.3, and 83.5 respectively. The completeness of learning and learning improvement is the achievement of learning in PBL classes.

\section{REFERENCES}

[1] P. Hallinger and E. M. Bridges, "A Systematic Review of Research on the Use of Problem-Based Learning in the Preparation and Development of School Leaders," Educ. Adm. Q., vol. 53, no. 2, pp. 255-288, 2017.

[2] L. Baron, J. Preston-Sabin, and D. Kennedy, "Problem-Based Learning for the Pre-service Teacher," SRATE J., vol. 22, no. 2, 2013.

[3] L. Hemker, C. Prescher, and S. Narciss, "Design and Evaluation of a ProblemBased Learning Environment for Teacher Training," Interdiscip. J. Probl. Learn., vol. 11, no. 2, Jul. 2017.

[4] T. Erdogan, "Research Trends In Dissertations On PBL: A Content Analysis Study," in Procedia - Social and Behavioral Sciences, 7th World Conference on Educational Sciences, (WCES-2015), 2015, pp. 308-315.

[5] D. E. Allen, R. S. Donham, and S. A. Bernhardt, "Problem-Based Learning," New Dir. Teach. Learn., no. 128, pp. 2129, 2011.

[6] R. Phungsuk, C. Viriyavejakul, and T. Ratanaolarn, "Development of A Problem-Based Learning Model Via A Virtual Learning Environment," Kasetsart J. Soc. Sci., vol. 38, 2017.

[7] N. Hirca, "Impact Of Problem-Based Learning to Students and Teachers," Asia-Pacific Forum Sci. Learn. Teach., vol. 12, no. 1, 2011.

[8] E. Ersoy and N. Baser, "The Effects of Problem-Based Learning Method in Higher Education on Creative Thinking," Procedia-Social Behav. Sci., vol. 116, pp. 3494-3498, 2014.
[9] B. Aidoo, S. K. Boateng, P. S. Kissi, and I. Ofori, "Effect of Problem-Based Learning on Students' Achievement in Chemistry," J. Educ. Pract., vol. 7, no. 33, 2016.

[10] B. B. Yazar Soyad1, "Creative and Critical Thinking Skills in Problem-based Learning Environments," J. Gift. Educ. Creat., vol. 2, no. 2, pp. 71-80, 2015.

[11] E. D. Graaff and A. Kolmos, "Characteristics of Problem Based Learning," Int. J. Engng, 2003.

[12] S. Nargundkar, S. Samaddar, and S. Mukhopadhyay, "A Guided ProblemBased Learning (PBL) Approach: Impact on Critical Thinking," J. Innov. Educ., vol. 12, no. 2, 2014.

[13] T. Y. Chuan and Et.al, "). Problem-Based Learning: With or Without Facilitator," Procedia Soc. Behav. Sci., vol. 18, pp. 394-399, 2011.

[14] V. J. Skinner, A. Braunack-Mayer, and T. A. Winning, "The Purpose and Value for Students of PBL Groups for Learning," Interdiscip. J. Probl. Learn., vol. 9, no. 1, 2015.

[15] J. R. Savery, "Overview of Problembased Learning: Definitions and Distinctions," Interdiscip. J. Probl. Learn., vol. 1, no. 1, 2006.

[16] P. Brown, "Theme: The 21st Century Adult Learner," Acad. Journals, vol. 12, no. 8, pp. 540-548, 2017.

[17] V. Hatisar and A. G. Küçükturan, "Vocational and Technical Education Problem-Based Learning Exercise: Sample Scenario," Procedia Soc. Behav. Sci. World Conf. Educ. Sci., pp. 19441948, 2009.

[18] M. J. Dondlinger and J.. McLeod, "Solving Real World Problems with Alternate Reality Gaming: Student Experiences in the Global Village Playground Capstone Course Design," Interdiscip. J. Probl. Learn., vol. 9, no. 2, 2015.

[19] E. Ceker and F. Ozdamli, "Features and characteristics of problem based Learning," J. Educ. Sci., vol. 11, no. 4, pp. 195-202, 2016. 
[20] D. Ku and C. Chang, "A framework of PBL strategy integrated in LMS and a Ubiquitous Learning Environment," in Sixth International Conference on Networked Computing and Advanced Information Management, 2010, pp. 722 726.

[21] L.. Drăghicescu, P. A-M, G. Gorghiu, and L.. Gorghiu, "Science as an Integrated Approach - A Démarche Focused on Promoting the Competencies for Life," Procedia - Soc. Behav. Sci., vol. 116, pp. 49-55, 2014.

[22] R. Fogarty, Problem Learning \& Other Curiculum Models for the Multiple Intelligences Clasroom. Pearson: SkyLight, 1997.

[23] O.-S. Tan, "Enhancing Thinking through Problem-Based Learning Approaches: International Perspectives," Singapore, 2004.

[24] N. Phumeechanya and P. Wannapiroon, "Design Of Problem-Based With Scaffolding Learning Activities in Ubiquitous Learning Environment to Develop Problem-Solving Skills," Procedia - Soc. Behav. Sci. World Conf. Educ. Sci. - WCES, vol. 116, pp. 48034808, 2014.

[25] S. Sharma, "Constructivsm: A New Paradigm in Education," Edusearch, vol. 3, no. 2, pp. 0976-1160, 2012.

[26] R. McTaggart, Action Research A Short
Modern History. Victoria: Deakin University Press, 1991.

[27] S. Kemmis and R. McTaggart, The Action Research Planner. Victoria: Deakin University Press, 1988.

[28] Elliott, Action Research for Educational Change. UK: McGraw-Hill Education, 1991.

[29] S. Hande, C. A. Mohammed, and R. Komattil, "Acquisition of Knowledge, Generik Skill, and Attitudes through Problem-Based Learning: Student Perspectives of A Hybrid Curriculum," J. Taibah Univ. Med. Sci., pp. 1-5, 2014.

[30] G. B. Leighbody and D. M. Kidd, Methods of Teaching Shop and Technical Subject. New York: Delmar Publishers, 1968.

[31] D. Mardapi, Teknik Penyusunan Instrumen Tes dan Non Tes. Yogyakarta: Mitra Cendekia Press, 2008.

[32] S. Bahera, "M-learning: a New Learning Paradigm," Int. J. New Trend Educ. Their Implic., vol. 4, no. 2, pp. 24-34, 2013.

[33] R. Sagor, The Action G Research Guidebook: A Four-Step Process for Educators and School Team. New Delhi: A Sage Publication Company, 2005.

[34] J. W. Creswell, Research Design: Qualitative, Quantitative, and Mixed Methods Approaches. Sage Publications, 2009. 